\title{
Transit Response to Congestion Pricing Opportunities: Policy and Practice in the U.S.
}

\author{
Matthew H. Hardy \\ Noblis
}

\begin{abstract}
This research assesses how U.S. transit agencies have taken advantage of congestion pricing projects and answers two questions: (1) what role has transit played in U.S. congestion pricing projects, and (2) how have transit agencies responded to congestion pricing projects through service planning, operating practices, capital investment, and institutional arrangements. First, transit is seen as a direct beneficiary of congestion pricing projects since transit systems operate free of charge, thereby achieving a more reliable and/or faster travel time, thereby as well as facilitating a shift to a higher occupancy mode (buses). Second, a micro-level analysis comparing two congestion pricing projects in Northern Virginia is made.
\end{abstract}

\section{Introduction}

Congestion pricing is designed to reduce traffic congestion by charging users a higher fee when roads are busier and a lower fee when they are not and is based upon fundamental economic principles of allowing market forces and pricing to allocate the use of finite transportation system capacity (Rouwendal and Verhoef 2006). The primary intent of congestion pricing is to mitigate the effect of too much demand on the roadway infrastructure and ensure efficient system utilization. Historically, two concerns of deploying congestion pricing projects in the 
United States have been technical feasibility and political acceptability (Giuliano 1992). While technical feasibility has been addressed through the development of open-road tolling and other ITS technologies, political acceptability has not been fully addressed.

Concerning political acceptability, in the commissioned paper Curbing Gridlock: Peak-Period Fees to Relive Congestion, Kain (1994) suggests that little political attention had been given to transit in the past because the effects are complex and require a number of assumptions that are difficult to defend. However, recent experience suggests two components concerning the political acceptability of congestion pricing projects related to transit. First, transit is seen as a direct beneficiary of congestion pricing projects since transit systems operate free of charge, thereby achieving a more reliable and/or faster travel time, thereby facilitating a shift to a higher occupancy mode (buses). For example, according to Small's (2005) assessment of London's congestion pricing system, “...better [transit] service was made possible, desirable, and financially viable by congestion pricing itself." Second, transit addresses the concern of fairness (or social equity) regarding the use of publically-funded transportation infrastructure (Giuliano 1994). Concerns about social equity center around the effect that congestion pricing may have on lowerincome groups ${ }^{1}$ (Viegas 2001). Recently, an NCHRP study regarding the public opinion of congestion pricing projects articulates social equity as a key concern of the public as well as how revenue generated by the project is used ( $Z$ mud and Arce 2008). Weinstein and Sciara conclude that social equity has a tendency to shape the overall design of the project, which often includes spending the revenue generated on alternate transportation options for users (Weinstein and Sciara 2006).

Thus, it would appear that including transit in the planning and design of congestion pricing projects appears to be essential to make it politically tenable. If congestion pricing projects require some type of transit involvement, the question becomes, with more than 15 years having passed since the U.S. implemented its first congestion pricing system in California, what role has transit really played? New initiatives by the U.S. Department of Transportation (U.S.DOT), including more than $\$ 1$ billion to further demonstrate congestion pricing in the U.S., provide the opportunity to address this question more in-depth. Additionally, two congestion pricing projects using private equity being constructed in the Commonwealth of Virginia that will bring on-line nearly 150 lane-miles of congestion pricing by 2013 further add to the available data from which to draw. This paper addresses the following two research questions: 
1. What role has transit played in U.S. congestion pricing projects currently in the operation, construction, or design stage of the project life-cycle?

2. How have transit agencies responded to congestion pricing projects through service planning, operating practices, capital investment, and institutional arrangements?

\section{Methodology and Data}

These research questions are investigated through a macro- and micro-level analysis of congestion pricing projects in the U.S. First, a macro-level analysis of 21 congestion pricing projects that were either operating or in the design/construction stage of the project life-cycle were identified based upon interviews with people at the federal, state, and local levels. This research purposefully excluded those projects in the planning stage since the overall role of transit was either too early to assess or too vague in nature to be of any value. Second, for each of the 21 projects, data were gathered regarding overall project characteristics from a number of sources, including planning documents, federal project applications, interviews with key project personnel, and project evaluations. Third, a ranking was given to each regarding both the involvement and impact of transit within the project. Finally, a micro-level analysis of two Virginia congestion pricing projects was undertaken. This analysis includes a more detailed review of the available planning documents associated with the projects and in-depth interviews with key personnel, including the Virginia Department of Transportation (VDOT) multimodal liaison, transit agency planning staff, and the metropolitan planning organization transportation director.

The congestion pricing projects included in this assessment are listed in Table 1, sorted according to operational year and including the following relevant data:

1. Location

2. Length

3. Type-Type of congestion pricing project based upon the U.S. DOT Federal Highway System classification system: variably priced lanes (VPL), variable priced toll road (VP-TR), cordon pricing (CP), or area-wide pricing (AWP).

4. Status

5. Operational Year 
6. System Type-New construction (New) or conversion of existing roadway (Conversion).

7. Operations-Privately- or publicly-operated system.

8. Transit Involvement-A ranking of transit involvement in the overall congestion pricing project planning and design that was conducted independently by the author using available documents, reports, presentations, conference proceedings and discussions.

- Low-No existing transit service in the congestion pricing corridor. No mention of transit as an important element in the planning documents.

- Medium-Existing transit service in the congestion pricing corridor. Transit mentioned as an important element within the documents reviewed. Revenue from congestion pricing could be used to offer alternatives but no additional funding has been identified for transit improvements.

- High-Existing transit service in congestion pricing corridor. Funding is codified in state law for transit improvements or funding for transit improvements have been identified and made available.

9. Transit Impact-An assessment of the overall impact of transit because of the congestion pricing project. The assessment is based upon Kain's (1994) analysis of transit's likely response to congestion pricing which includes improvements in speed, reliability, ridership and load factors as well as an overall expansion of service.

- Not Significant (Not Sig.)-Transit service has been unaffected by the congestion pricing project (e.g., no improvement or service expansion).

- Significant (Sig.)-Transit service has been improved as a result of the congestion pricing either through improved service and expanded operations.

10. Transit Revenue Source-Source of transit funding. 


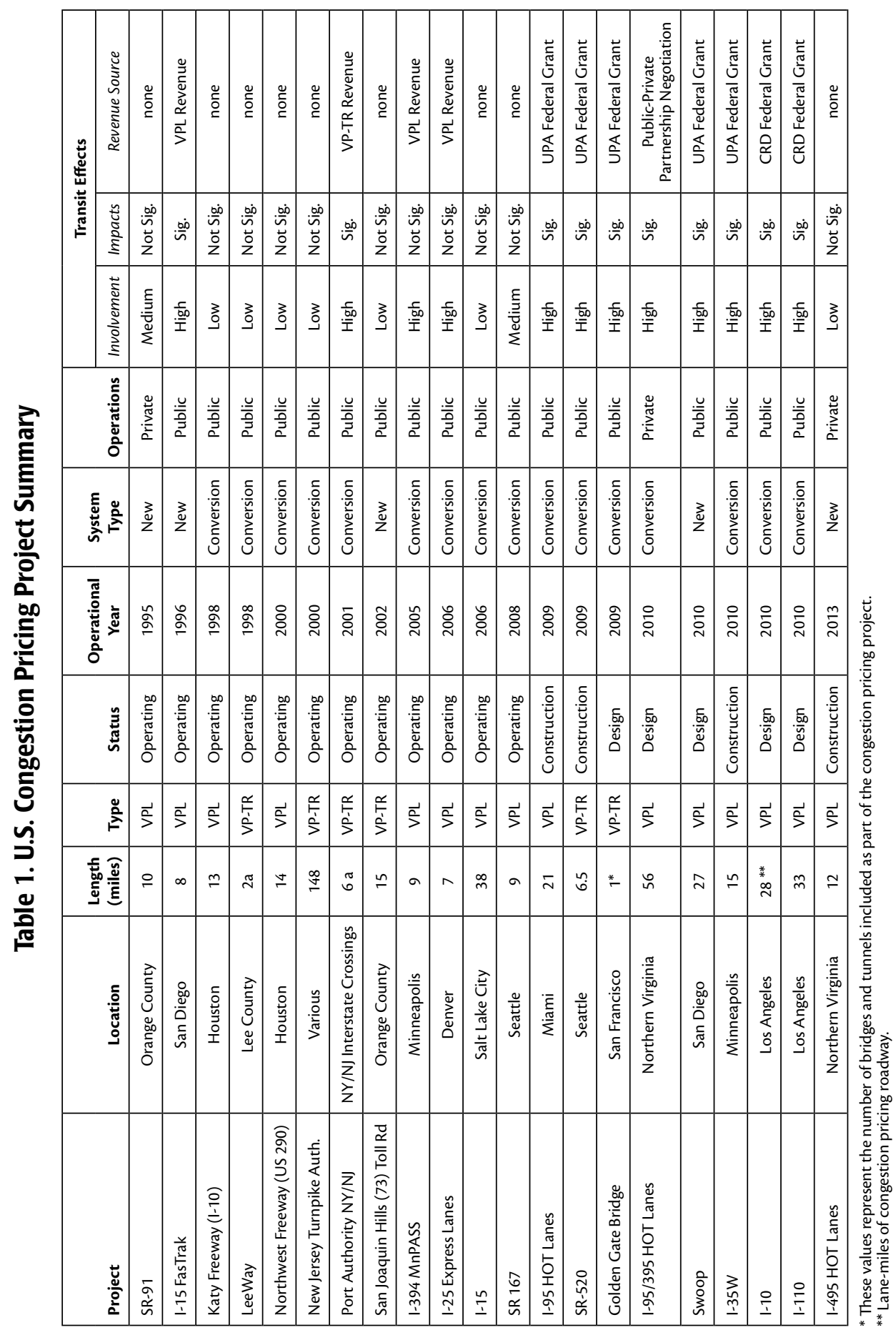




\section{Macro Assessment of Transit Role in Congestion Pricing Projects}

As seen in Table 1, the involvement of transit shows 13 of the 21 projects receiving a rank of High, while two were ranked Medium, and seven ranked as Low. This indicates that as part of the project design stage, transit has played an important role in shaping the congestion pricing project. For example, the I-15 project in San Diego was implemented as a tool to use available capacity on the HOV lanes on I-15 between Poway and San Diego as well as provide a revenue source to fund new transit service along the same corridor (Hultgren and Kawada 1999). Thus, transit had a vested interest in the success of the project. Other examples of high involvement include projects in Colorado and Minnesota, both of which have legislation indicating that excess revenue generated by the projects can be used to fund transit service within the corridor. Finally, there are the eight congestion pricing projects funded as part of the U.S. DOT's Fight Gridlock Now program, which includes large federal grants to demonstrate congestion pricing as well as fund transit service as an integral part of those projects.

While transit involvement in congestion pricing projects appears to be substantial, the reality of how transit has been affected by these projects is quite different. An initial review of the data in Table 1 indicates that the impact on transit has been substantial with 50 percent of the projects receiving a ranking of Significant and 50 percent receiving a ranking of Not Significant. Taken in isolation, this would indicate that most transit systems significantly benefit from congestion pricing projects. However, a more careful assessment shows something remarkably different. First, of the 12 operational projects, only 2 have had a significant impact on transit (compared to 4 of the 12 having a ranking of High in terms of transit involvement). This indicates that while the potential for transit is high (measured by transit involvement), the reality is that the impact on transit has not been significant for the operational projects (measured by transit impact).

Second, examining those projects in the design or construction stage reveals that each one receiving an involvement ranking of High also received a transit impact ranking of Significant. The reason is the revenue source for the transit improvements. All of the projects receiving a Significant ranking for transit impact that are in the design and construction stage have a dedicated lump-sum source of revenue that will be used to make the transit improvements. These projects do not rely on the variability of revenue generated by the congestion pricing project through tolls and user fees. All but one of the non-operational projects will use a federal 
grant as the means to make the transit improvements. The funding arrangement of the non-operational projects is in contrast to the operating congestion pricing projects where those projects receiving a transit involvement ranking of High rely on revenue generated by the congestion pricing projects to make transit improvements, with only two of the four receiving a transit impact rating of Significant.

In the four cases where transit involvement was ranked High, all relied on revenue generated by the congestion pricing project to fund transit improvements. Only two of the four projects resulted in significant impact to transit operations. The first is the Port Authority of NY/NJ, which implemented congestion pricing on the six interstate crossings and has produced a significant increase in funding for transit. The second is the $1-15$ congestion pricing project in San Diego, where revenue was used to establish a new transit service in the corridor. The other two operational congestion pricing projects (1-394 MnPASS and I-25 Express Lanes) have not generated enough revenue to cover operational costs, let alone provide additional funding for transit improvements in the corridor.

The results of this macro-level analysis revealed three common themes among the 21 projects:

1. Transit involvement is high, but long-term opportunities are lacking-Half of the operational congestion pricing projects that include high opportunities for improved transit service as part of state enabling legislation have not provided any revenue to the transit agency. Of the 9 non-operational systems, none include specific language as to sources of revenue for improved transit service beyond those made available as part of an initial federal grant or project negotiation. The lack of on an ongoing revenue source indicates that while transit is perceived to have an important role in the overall project, the long-term impact is by no means guaranteed.

2. Congestion pricing projects with significant transit impact include a dedicated funding source, not just a portion of revenue-Transit has been included as a key player in many congestion pricing projects that are either operating or in the design/construction stage. However, there is a clear distinction between the potential for transit (indicated by its involvement) and the overall impact it has. Generally, those congestion pricing projects with a significant impact on transit included a dedicated source of funding independent of the expected revenue generated. 
3. Transit must be a major partner - In the two operational systems where transit had a significant impact, transit was an important project partner even though the role was different for each. One of the stated goals of the Port Authority of $\mathrm{NY} / \mathrm{NJ}$ congestion pricing project was to encourage use of mass transit in corridors with transit alternatives along with reducing traffic congestion. A similar set of goals was established for the I-15 FasTrack system. However, the same is not true for the other operational congestion pricing projects. For example, the Katy Freeway in Houston has the goal of utilizing excess capacity on the HOV lanes and the LeeWay project has the goal of reducing peak-period demand.

\section{Micro Assessment of Transit Role in Congestion Pricing Projects}

The second dimension of this assessment is to assess how transit agencies have responded to congestion pricing projects through service planning, operating practices, capital investment and institutional arrangements. Based on the data gathered from the 22 congestion pricing projects in the U.S., this was difficult to accomplish since only the I-15 FasTrak system in San Diego included the operation of new transit service as a direct response to the congestion pricing system being implemented. The other congestion pricing project with significant transit impacts, Port Authority of NY/NJ, did not include any major modification to service planning, operating practices, or institutional arrangements as a result of the project. $^{2}$

However, what was gleaned from the data gathering and assessment was an interesting difference between the two congestion pricing projects currently being designed and constructed in northern Virginia. These two projects will add more than 150 lane-miles of priced lanes to the region along some of the most highlycongested corridors. Both are being constructed using private equity under the Virginia Public Private Transportation Act (PPTA). While the 1-95/395 HOT Lanes include more than $\$ 195$ million in funding for improved transit service, the $1-495$ HOT Lanes project includes no monies. The following case study assessment provides an overview of each project and concludes with an analysis comparing and contrasting the two. 


\section{Northern Virginia Congestion Pricing Project Summaries ${ }^{3}$}

\section{I-495 Capital Beltway HOT Lanes}

Construction of the 1-495 HOT Lanes began in summer 2008 with an expected completion date of 2013. The congestion pricing project will include the construction of four new variably-priced lanes along the Virginia section of the Capital Beltway between the Springfield Interchange and just south of Georgetown Pike. A consortium led by Flour-Transurban is financing and constructing the entire 14-mile project. When completed, the HOT lanes will allow transit and HOV-3 vehicles to travel free, while SOV and HOV-2 vehicles will pay a variable toll based on current travel demand to provide free-flow travel conditions. The Flour-Transurban consortium will hold a 75-year operating lease with any financial success (above and beyond benchmarks set forth in the PPTA agreement) shared with the Commonwealth of Virginia.

Initial acceptance of the HOT lanes project ran into local government and community opposition based on the perceived exclusiveness of the lanes ("Lexus Lanes"), limited community involvement, and the lack of support for alternative modes of transportation (Hardy 2008). To address these concerns, the Flour-Transurban consortium began to include more community involvement and highlight the benefits to other transportation modes. For example, the literature describing the project labeled the HOT lanes as "HOV/Bus/HOT Lanes" to promote the multimodel nature of the project. Also, the consortium emphasized the infrastructure improvements being made will create more bicycle and pedestrian access points that currently do not exist on many of the bridges crossing the Capital Beltway.

However, the role of transit within the HOT lanes project is still small, which may be a reflection of current transit service along this section of the Capital Beltway. Currently, no transit service operates on this section of the beltway due primarily to the unreliability of travel times even though two of the largest employment centers and housing areas within Fairfax County are located at either ends of the project: Springfield and Tysons Corner. The only transit service serving these two areas is Fairfax Connector Bus 401 operating on thirty-minute headways but using local streets adjacent to the beltway. Fairfax County (operator of the Fairfax Connector bus service) is currently creating a ten year long range bus plan and intends to incorporate the availability of the HOT lanes into this plan (Fairfax County Department of Transportation 2008). The Potomac Rappahannock Transportation Commission (PRTC) has listed the unreliability of travel time on the Capital Beltway as one reason they do not provide service to Tyson's Corner from southern Prince William County 
(Marx 2008). Ironically, however, PRTC will be operating an express bus service during construction of the 1-495 HOT Lanes between Springfield and Tyson's Corner as part of the work zone transportation management plan to mitigate mobility impacts as a result of the construction (Pardo 2008). Whether these express bus routes remain after construction is complete is not known.

\section{I-95/395 HOT Lanes ${ }^{5}$}

The I-95/395 HOT Lanes congestion pricing project will expand existing HOV lanes located on both $1-95$ and $1-395$ from two to three lanes and extend the lanes into Spotsylvania County near Fredericksburg. The HOT lanes will be variably priced and switch direction based upon peak period demand (northbound in the morning and southbound in the evening). Once complete, users will be able to use the HOT lanes for 56 miles from Fredericksburg to Washington, D.C. The project is being pursued under the Virginia PPTA by the Flour-Transurban consortium where private equity will be used to build-operate-maintain the HOT lanes for a 75-year lease period with any financial success (above and beyond benchmarks set forth in the PPTA agreement) shared with the Commonwealth of Virginia.

The 1-95/395 corridor is currently used by many different transit agencies and operators including private bus service, express buses, local buses, heavy rail and commuter rail. In addition, there are numerous park-and-ride lots and subsequent slug lines (ad hoc carpools formed on-the-fly at commuter park-and-ride lots along 1-95). In a reflection of transit's heavy use within the corridor, the I-95/395 HOT lanes project includes a number of direct benefits to transit users, including infrastructure improvements such as more on/off ramps that will enable faster travel times, new transit stations, additional roadway capacity and a contribution by Flour-Transurban towards capital investment for transit (purchase of buses, construction of park-ride-lots, etc.). Because of this contribution, negotiated as part of the PPTA agreement, the Commonwealth Transportation Board instructed the Virginia Department of Rail and Public Transportation (VDRPT) to develop a comprehensive transit/TDM study for the corridor to better determine how the available funding could be used (VDRPT 2008).

\section{Project Comparison and Analysis}

While the two Virginia congestion pricing projects appear to be similar in terms of location, institutional arrangements, and the use of private equity to design-buildoperate, the overall impact to transit is very different. Table 2 provides a summary of the differences and commonalities between the two projects as they relate to transit impacts. 


\section{Table 2. Comparison of Transit Impacts for Virginia Congestion Pricing Projects}

\begin{tabular}{|c|c|c|}
\hline & I-495 HOT Lanes & I-95/395 НОТ Lanes \\
\hline Existing Transit Service & $\begin{array}{l}\text { Route } 401 \text { bus service } \\
\text { (approximately } 2 \\
\text { buses per hour during } \\
\text { the service period) }\end{array}$ & $\begin{array}{l}\text { - } 127 \text { buses per hour (peak) } \\
\text { - } 10 \text { Metrorail trains per hour } \\
\text { - } 2 \text { Virginia Railway Express (VRE) trains } \\
\text { every hour } \\
\text { - } 2 \text { Amtrak trains (peak) }\end{array}$ \\
\hline $\begin{array}{l}\text { Operating Agencies and } \\
\text { Services within Corridor }\end{array}$ & - Fairfax Connector & $\begin{array}{l}\text { - Potomac and Rappohannock } \\
\text { - Transportation Commission } \\
\text { - Washington Metropolitan Area Transit } \\
\text { Authority } \\
\text { - Virginia Railway Express } \\
\text { - Fairfax County } \\
\text { - AMTRAK } \\
\text { - City of Alexandria } \\
\text { - Arlington County } \\
\text { - Fredericksburg Regional Transit } \\
\text { - Private Commuter Bus } \\
\text { - Slug Lines } \\
\text { - Park-and-ride Lots }\end{array}$ \\
\hline Construction Type & - New & $\begin{array}{l}\text { - Conversion } \\
\text { - New }\end{array}$ \\
\hline Long-Range Planning & $\begin{array}{l}\text { - Included in Constrained } \\
\text { Long-Range Plan }\end{array}$ & - Included in Constrained Long-Range Plan \\
\hline Service Planning & $\begin{array}{l}\text { Fairfax County includ- } \\
\text { ing new transit service } \\
\text { options on 1-495 } \\
\text { HOT lanes as part of } \\
\text { a } 10 \text {-year long-range } \\
\text { bus plan }\end{array}$ & $\begin{array}{l}\text { - Extensive Transit/TDM Study conducted } \\
\text { to determine most effective use of transit } \\
\text { service on HOT lanes } \\
\text { - Local agencies incorporating into service } \\
\text { planning }\end{array}$ \\
\hline Operating Practices & $\begin{array}{l}\text { - New express bus being } \\
\text { implemented as part of } \\
\text { work zone transporta- } \\
\text { tion management plan }\end{array}$ & - New BRT service being considered \\
\hline Institutional Arrangements & - PPTA & $\begin{array}{l}\text { - PPTA } \\
\text { - VDRPT took lead role in developing } \\
\text { Transit/TDM Study }\end{array}$ \\
\hline Capital Investment into Transit & - None & - \$195 million lump sum payment \\
\hline OnGoing Revenue Source* & - Potential for revenue & - Potential for revenue \\
\hline $\begin{array}{l}\text { Direct Benefits to Transit } \\
\text { Improvements }\end{array}$ & $\begin{array}{l}\text { - Transit operates free } \\
\text { on HOT lanes }\end{array}$ & $\begin{array}{l}\text { - Transit operates free on HOT lanes } \\
\text { - } 28 \text {-mile southern extension of existing } \\
\text { HOV lanes } \\
\text { - } 3,000 \text { new park-and-ride spaces in the } \\
\text { corridor } \\
\text { - } 33 \text { new entry/exit ramp facilities } \\
\text { - In-line BRT station in Lorton } \\
\text { - Enhancements to } 12 \text { existing bus stations }\end{array}$ \\
\hline
\end{tabular}

*Both projects include revenue sharing clauses that will provide Virginia with a portion of the revenue generated above certain benchmarks. 
As seen in Table 2, there are a number of commonalities between the two projects. First, both are constructed under the Virginia PPTA and include a clause that enables Virginia to benefit from any success of the HOT lanes in terms of revenue generation above and beyond what is stipulated in the agreements. Thus, if demand is higher than projected there is the potential for an additional revenue source for Virginia; but, whether it would be spent on transit is not known. Second, both projects have been included in the regional constrained long-range plan, meaning they will be taken into account as part of the regional travel demand modeling efforts and service planning. Third, in both projects, transit will be able to use the HOT lanes free of charge. In the case of the $1-495$ project, this means new infrastructure on which to operate. For the $1-95 / 395$ project, this means additional capacity and access points. Finally, construction of both will include new roadway infrastructure, and the $1-95 / 395$ project also includes conversion of existing HOV lanes to HOT lanes. Previous congestion pricing projects that have converted existing HOV lanes to HOT lanes have included concerns about the impact on transit. For example, the SR 167 HOT lanes included construction of barrier separation which forced transit buses to alter their travel patterns on the lanes. However, conversion on 1-95/395 will not have similar concerns since additional entry and exit points are being constructed.

What is most striking in Table 2 are the differences between the two projects in terms of existing transit service and the number of operating agencies within the corridor. The 1-95/395 HOT lanes includes significantly more transit service and agencies compared with the $1-495$ HOT lanes project, which may have been a major factor in VDOT negotiating with the Flour-Transurban consortium a \$195 million contribution towards transit improvements within the corridor as part of the PPTA. In addition, the existence of a strong transit user base more than likely contributed to the need to better articulate exactly how transit users would benefit as part of the 1-95/395 HOT lanes project. With the I-495 project, no transit user base existed except for a local bus service that operated on streets adjacent to the Capital Beltway. Thus, when an assessment was made as to current demand for transit among the three major activity centers (Springfield, Merrifield, and Tyson's Corner), there were little data to use except the single bus route and speculation as to what type of demand may be created by the HOT lanes. However, with the I-95/395 HOT lanes, the amount of existing demand was easily calculated along with future demand for new transit service. 
The micro-level analysis of the two Virginia congestion pricing projects revealed the following observations:

1. Establishing a transit user base is important-On one hand, for transit to be an integral player, an existing user base needs to be established. The 1-95/395 project had a tremendous number of existing transit users whose concerns had to be addressed for the project to move forward. A similar transit user base was not identified for the $1-495$ project. On the other hand, congestion pricing projects could stimulate a new transit user base to be formed if the system were designed to take advantage of the transportation infrastructure. For example, the $1-495$ HOT lanes would create a corridor with more reliable and faster travel times for buses, enabling Fairfax County to establish new transit service, thereby establishing a new user base.

2. Transit agencies need to adapt quickly to congestion pricing projects-Both the 1-95/395 and I-495 HOT lanes projects have moved forward very quickly considering the length of time each has been in the planning stage. This presents a barrier to many transit agencies that are not able to adapt to such an aggressive schedule. In the case of the $1-495$ HOT lanes, the local operating agency has just begun to incorporate the new facility into its operations. A similar observation can be made of the 1-95/395 project, where VDRPT has produced an overall study about new transit service in the corridor but no changes have actually been made. The speed with which VDRPT has moved is in contrast to VDOT, which very quickly adapted to the congestion pricing proposals when they were submitted.

3. Transit agencies need to consider innovative operations-There is little evidence to suggest that any types of new or innovative operating practices are being considered for the Virginia HOT lanes, which may be one of the more critical elements to ensuring transit benefits from congestion pricing. Taken together, the two Virginia congestion pricing projects provide an example of a network-based HOT lane application where new transit service could operate (Poole and Orski 2003). However, it requires extensive planning and changes to existing operations and infrastructure. For example, a bus rapid transit (BRT) network could be established between Springfield and Tyson's Corner with in-line stations along the HOT lanes right-of-way and pedestrian access via the bridges going over the roadway. Establishing a BRT network that incorporates innovative operations, however, requires forethought prior to final design and construction. 


\section{Conclusions}

The purpose of this research was to assess how U.S. transit agencies have taken advantage of opportunities provided by congestion pricing projects. The macrolevel assessment of the 21 U.S. congestion pricing projects shows that while transit agencies have been included as important players, they have not had an active role to date. Of the 12 operating congestion pricing projects, only two have seen any type of significant impact on transit. Thus, while the involvement of transit has been significant in congestion pricing projects, the overall impact on transit has been small. This is an important finding since much of the literature states that congestion pricing could be a means to better fund transit operations. What this analysis found is that very few congestion pricing projects resulted in long-term, ongoing sources of revenue for a transit agency to provide new service or improve existing service.

However, the establishment of the U.S. DOT Urban Partnership Agreements and Congestion Reduction Demonstration programs may prove otherwise since a significant amount of the federal grants associated with these projects will directly benefit transit agencies. But, in terms of long-term opportunities for transit (e.g., new revenue sources for capital and operating expenses) none of these projects has demonstrated that to be a reality. For example, while creating a new source of revenue may be more attractive to transit agencies since many are heavily subsidized, a congestion pricing project will not guarantee this revenue stream. As seen with the I-394 MnPASS project, even though the law requires 50 percent of revenue to be spent on transit within the corridor, current revenue generated by the tolls has not covered the cost to build, operate, and maintain the system (Howard 2005). Thus, guaranteed lump sum payments, such as those being provided as part of the U.S. DOT Urban Partnership Agreements, may be a more attractive option to address immediate needs.

The results of the Virginia case study analysis yield interesting results about transit's response to congestion pricing projects. In comparing these two projects, there is evidence to suggest that transit agencies operating along the 1-95/395 corridors have taken into account the potential opportunities made available to them to improve transit service as a result of the HOT lanes. In fact, VDRPT conducted a comprehensive analysis of transit opportunities as a result of the 1-95/395 HOT lanes, but a similar study for the I-495 HOT lanes was not conducted. Recently, however, Fairfax County did begin developing a 10-year long-range bus operation plan that will take into account the two Virginia HOT lanes projects. 
Overall, as more congestion pricing projects are implemented in the U.S., it will be important to collect data and continually monitor and evaluate the role of transit within congestion pricing projects to ensure that social equity is being addressed. The two limitations of this research center upon the availability of data. First, there was little formal evaluation data concerning existing congestion pricing systems and the impact on transit. Many of the systems had limited data, but no detailed assessment (e.g., before/after analysis) of transit operations. Second, the microlevel analysis of the two Virginia projects does not provide a complete picture of all types and flavors of congestion pricing in the U.S. However, this was an opportunity to make a true apples-to-apples comparison to examine transit agency response to congestion pricing projects. Future research should include more case studies at this level of analysis.

\section{Endnotes}

${ }^{1}$ For a more detailed discussion, see Litman (2005), Small (2002), Weinstein and Sciara (2006), and Viegas (2001).

${ }^{2}$ This should not be construed as a negative aspect of the project. The New York City metropolitan region already has the highest transit usage rate in the U.S., and any additional funding for operations and maintenance is important.

${ }^{3}$ The description and discussion of the I-495 and I-95/395 HOT Lanes projects was developed based upon an interview with Ms. Valerie Pardo, VDOT Multimodel Liason, on July 3, 2008.

${ }^{4}$ A more detailed description of the I-495 Capital Beltway HOT Lanes project is available at http://www.virginiahotlanes.com/beltway-project-info.asp.

${ }^{5}$ A more detailed description of the 1-95/395 HOT Lanes project is available at http://www.virginiahotlanes.com/i95-project-info.asp.

\section{References}

Fairfax County Department of Transportation. 2008. Fairfax Connector and Fairfax Metrobus Service Transit Development Plan (TDP). Public meetings presentation, 29 April 2008 - 4 June 2008. http://www.fairfaxcounty.gov/fcdot/pdf/ tdp/presentation_spring08.pdf. 
Giuliano, G. 1992. An assessment of the political acceptability of congestion pricing. Transportation 19: 335-358.

Giuliano, G. 1994. Equity and fairness considerations of congestion pricing. In Curbing gridlock: Peak-period fees to relieve traffic congestion. Washington, DC, Transportation Research Board.

Hardy, M. 2008. A multiple streams analysis of the rise of congestion pricing policies and the urban partnership agreements. ITS World Congress, New York, NY.

Howard, C. 2005. Report on MnPASS I-394 HOT Lane Project. Washington State Transportation Commission.

Hultgren, L., and K. Kawada. 1999. San Diego's Interstate 15 high-occupancy/toll lane facility using value pricing. ITE Journal.

Jones, J. D., and J. Webb. 2007. Funding new infrastructure: Virginia's Public Private Transportation Act experience, 1995-2006. New Voices in Public Policy 1, Spring.

Kain, J. 1994. Impacts of congestion pricing on transit and carpool demand and supply. In Curbing gridlock: Peak-period fees to relieve traffic congestion. Washington, D.C., Transportation Research Board.

Litman, T. 2006. London congestion pricing: Implications for other cities. Victoria, BC, Victoria Transport Policy Institute.

Littman, T. 2005. Using road pricing revenue: Economic efficiency and equity considerations. Victoria, BC, Victoria Transport Policy Institute.

Marx, Eric. 2008. Personal discussion with Mr. Marx, Executive Director of the Potomac and Rappohannock Transportation Commission, 9 July, Washington, D.C.

Pardo, Valerie. 2008. Phone interview with Ms. Pardo, VDOT Multimodal Liaison, 3 July, Washington, D.C.

Poole, R. W., and C. K. Orski. 2003. HOT networks: A new plan for congestion relief and better transit. Reason Foundation.

Rouwendal, J., and E. Verhoef. 2006. Basic economic principles of road pricing: From theory to applications. Transport Policy 13: 106-114. 
Schrag, Z. M. 2006. The Great Society Subway: A History of the Washington Metro. Baltimore, MD, The Johns Hopkins University Press.

Schrank, D., and T. Lomax. 2005. The 2005 urban mobility report. Texas Transportation Institute.

Small, K. 1992. Using the revenues from congestion pricing. Transportation Research Part A 19: 359-381.

Small, K. 2005. Unnoticed lessons from London: Road pricing and public transit. Access 26 (Spring).

The State of Colorado. 1999. An Act Concerning High Occupancy Vehicle Lanes.

U.S. Department of Transportation. 2006. Congestion pricing: A primer. Federal Highway Administration.

VDRPT. 2008. I-95/395 transit/TDM study final report. Richmond, VA, I-95/I-395 Transit/TDM Technical Advisory Committee.

Viegas, J. M. 2001. Making urban road pricing acceptable and effective: Search for quality and equity in urban mobility. Transport Policy 8: 289-294.

Weinstein, A., and G. C. Sciara. 2006. Unraveling equity in HOT lane planning: A view from practice. Journal of Planning Education and Research 26.

Zmud, J., and C. Arce. 2008. Compilation of public opinion data on tolls and road pricing. Synthesis 377. National Cooperative Highway Research Program. Washington, D.C, Transportation Research Board.

\section{About the Author}

MATTHEW HARDY (matthew.hardy@noblis.org) is a Principal in the transportation division of Noblis, based in Washington, D.C. He is a graduate of George Mason University in Fairfax, Virginia, with a B.S. in Urban Systems Engineering and an M.S. in Transportation Policy, Operations and Logistics. He has conducted extensive research in the application of ITS technologies to BRT systems and Vehicle Assist and Automation systems for transit applications and was co-author of FTA's Characteristics of Bus Rapid Transit for Decision-Making. He is a member of the TRB committee on Vehicle Highway Automation and is currently pursuing a Ph.D. at George Mason University in the School of Public Policy. 